\title{
Secondary recurrent miscarriage and sex of previous child
}

\author{
Deepali Raina $^{1}$, Nivedita Prashar $^{1 *}$, Gopal Sharma ${ }^{2}$
}

\author{
${ }^{1}$ Department of Obstetrics and Gynaecology, SMGS Hospital, GMC Jammu, India \\ ${ }^{2}$ Department of Surgery, GMC Jammu, India
}

Received: 18 March 2016

Revised: 12 April 2016

Accepted: 13 April 2016

\section{*Correspondence:}

Dr. Nivedita Prashar,

E-mail: niveditaprasher@gmail.com

Copyright: (c) the author(s), publisher and licensee Medip Academy. This is an open-access article distributed under the terms of the Creative Commons Attribution Non-Commercial License, which permits unrestricted non-commercial use, distribution, and reproduction in any medium, provided the original work is properly cited.

\begin{abstract}
Background: Secondary Recurrent Miscarriage (SRM) is defined as occurrence of three or more spontaneous consecutive abortions following the birth of one child. Mothers of boys often get immunized against male-specific minor histocompatibility ( $\mathrm{H}-\mathrm{Y})$ antigens due to transfer of fetal cells into the maternal circulation. The birth of a boy is significantly more common than a girl prior to secondary recurrent miscarriage (SRM) and is known to be associated with a poorer chance of a subsequent live birth. Children born after Secondary Recurrent Miscarriage are more likely to be girls. Aberrant H-Y immunity may be a causal factor for SRM.

Methods: The study was conducted over a period of one year from January 2012 to December 2012. All the women presenting with full term pregnancy and previous history of unexplained, three or more spontaneous consecutive abortions at 8 to 20 weeks gestation were taken as cases. Sex of the previous child was sought. The patients were followed till delivery and sex of the child born subsequently was also noted. Association of history of SRM to sex of the previous and present child was calculated by appropriates statistical methods.

Results: A total of 34 patients with history of SRM were studied. 23 out of them had a previous male child and 11 had given birth to a female $(\mathrm{p}=0.004)$. The male: female sex ratio of children born prior and subsequent to SRM was 2.09 and 0.79 respectively.

Conclusions: Study supports the hypothesis that aberrant maternal H-Y immune response may have a pathogenic role in SRM.
\end{abstract}

Keywords: SRM, H-Y antigen, Reproductive immunology

\section{INTRODUCTION}

Recurrent miscarriage defined as a minimum of three consecutive miscarriages affects $1-3 \%$ of women. ${ }^{1,2}$ Approximately $40 \%$ of the women with recurrent miscarriage have given birth to a child prior to the series of miscarriage and are thus diagnosed with secondary recurrent miscarriage $(\mathrm{SRM}){ }^{3}$ A potential cause for the miscarriages is identified in less than half of cases following standard investigation4.An accumulation of several markers of immune dysfunction 5-9 or particular human leukocyte antigen (HLA) alleles. ${ }^{10.11}$ can be found in these women, pointing towards the involvement of the immune system in many cases of RM. There are some observations to support the theory that immunological factors play a greater role in women with a series of miscarriages after a birth (secondary RM) than in women with RM who had never had a successful pregnancy (primary RM). ${ }^{12}$ The remaining patients are diagnosed with unexplained recurrent miscarriage. During pregnancy, fetal cells enter the maternal circulation and in late pregnancy, apoptotic syncytiotrophoblast debris is normally shed in large quantities (several grams per day) from the placenta. Fetal microchimerism i.e. persistence of fetal cells in the mother after birth is a well-known process too. Also, anti-H-Y immunity, which may be either humoral or cellular, can be demonstrated up to 22 years after the birth of a boy in mothers. This can lead to 
priming of the immune system of the mothers that may theoretically lead to harmful immunological reactions against the semi-allogeneic fetus. A well-known example of immunization in an on-going pregnancy that can harm the fetus in subsequent pregnancies, is the production of maternal antibodies against the Rhesus antigen causing fetal erythroblastosis. Similarly, it is possible that maternal immunization against male-specific minor histocompatibility (H-Y) antigens carried by a male fetus in a pregnancy that went to the third trimester may harm (in particular male) embryos and fetuses in subsequent pregnancies. Anti H-Y immunity is also held responsible for the increased risk of graft-versus-host disease (GvHD) in male recipients of stem-cell transplantation with female donors. It has been seen that among patients with SRM, a boy prior to the series of miscarriages is significantly more common than a girl and previous male child also negatively influences the chance of a subsequent live birth among these patients, particularly the mothers who carry $\mathrm{H}-\mathrm{Y}$ restricted HLA class 11 alleles reflecting the participation of $\mathrm{CD} 4+\mathrm{T}$-cells in responses against $\mathrm{H}-\mathrm{Y}$ antigen. These $\mathrm{CD} 4+\mathrm{T}$-cells then activate $\mathrm{B}$ cells to secrete anti-HLA antibodies. This leads to occurrence of anti-HLA antibodies in increased frequencies in SRM cases compared to primary recurrent miscarriage and more so in the SRM cases with previous male child. Male to female sex ratio is elevated before SRM and it significantly decreases after SRM; suggesting that male embryos are preferentially miscarried. On the basis of these findings, it can be proposed that the aberrant $\mathrm{H}-\mathrm{Y}$ immunity initiated in a prior long-lasting male fetus pregnancy may be a causal factor for SRM.

\section{METHODS}

The study was conducted in the Department of Obstetrics and Gynecology SMGS Hospital, GMC Jammu over a period of one year.

All the consenting women with one previous child followed by history of three or more spontaneous consecutive abortions between 8 to 20 weeks of gestational age were selected as cases from those who were admitted in the emergency ward of the department.

\section{Exclusion criteria}

Parity $>1$

- $\quad$ Age $<20$ or $>35$ years

- Chronic hypertension

- Gestational or pre-gestational diabetes

- Any other chronic or debilitating illness

- Multi-fetal gestation (Previous or current)

- $\quad$ BMI $<19$ or $>30$

- Anemia (Hb<9 gm \%)

- Congenitally anomalous fetus (Previous or current)

- Previous Intrauterine death of fetus

- Known structural uterine and cervical abnormalities including Fibroids
- Uncontrolled hypothyroidism or hyperthyroidism

- Apparent maternal infections

- Chronic smoker, alcoholic or any other substance abuse

- $\quad$ Rh negative with ICT positive

- TORCH IgM and IgG positive

- APLA positive

- History of blood transfusion in the past

After selecting the cases, relevant history was sought from them. Sex of the previous child was also asked. General physical and obstetrical examination was done. All routine, case specific and other necessary investigations to rule out conditions falling in the exclusion criteria were done e.g.

- $\mathrm{Hb}$

- Blood group

- Blood sugar

- TSH

- APLA titers

- Obstetrical USG

- $\quad$ ICT in Rh negative women

- TORCH IgM \& IgG antibody titres

Comparison of frequency of occurrence of SRM was made with respect to sex of the previous child. Unfortunately none of the patient and their products of conception were subjected to karyotyping.

\section{RESULTS}

A total of 34 cases of SRM were obtained during the course of study. ${ }^{23}(67.65 \%)$ of these had a male baby previously. Only $11(32.35 \%)$ had given birth to a female first. Thus, SRM was more frequently seen in women who had given birth to a male child previously as compared to women with the previous female child ( $\mathrm{p}=$ 0.03) (Table 1). Fifteen patients gave birth to a male after having SRM while nineteen delivered a female baby this time. The Male: Female sex ratio of children born after SRM to same mothers was reversed and was 0.79 [15/19]. The male: Female sex ratio of children born prior to SRM was $2.09(23 / 11)$ (Table 2).

Table 1: Percentage distribution of previous child of patients.

\begin{tabular}{|lll|}
\hline Previous child & No. of patients & Percentage distribution \\
\hline Male & 23 & $67.65 \%$ \\
\hline Female & 11 & $32.35 \%$ \\
\hline Total & 34 & $100 \%$ \\
\hline
\end{tabular}

Table 2: Male: Female sex ratio of children born before and after SRM.

\begin{tabular}{|llll|}
\hline & Male & Female & M: F Sex ratio \\
\hline Para 1 & 23 & 11 & 2.09 \\
\hline Para 2 & 15 & 19 & 0.79 \\
\hline
\end{tabular}




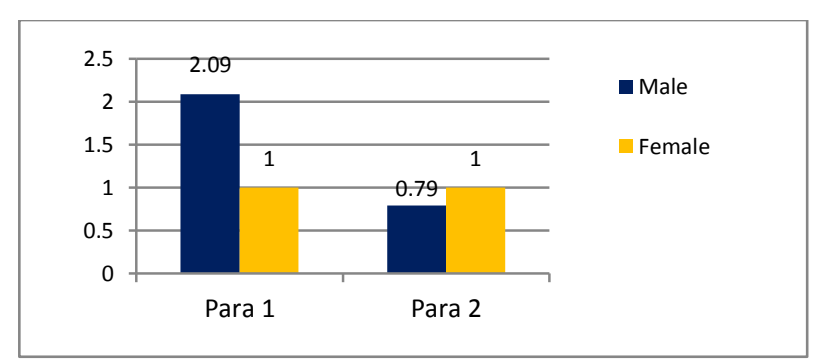

Figure 1: The M: $F$ ratio in para 1 and para 2 mothers.

Out of 34 cases of SRM, fourteen had early losses $(<10$ weeks of gestational age) whereas rest twenty females had late losses (>10 weeks of gestational age). In group of patients who had early losses, nine had previous male child and five had previous female child. Eight gave birth to male and six to female child this time. In other group of late miscarriages, fourteen had male child and six had female child as their first baby. This time, seven had male and thirteen had female child. Male: Female ratio in early losses group was 9/5(1.8) in Para 1 and it was 8/6(1.3) in Para 2. Ratio in late losses group was $14 / 6(2.3)$ at their first time and during second time it was 7/13(0.53). Ratio almost remains same in group 1 whereas it drastically reverses in group 2.

\section{DISCUSSION}

A possible explanation for the miscarriages is identified in less than half of the cases following standard investigations. Some of these unexplained miscarriages are the result of chromosomal abnormalities that are incompatible with survival. Supposedly, more SRMs than primary recurrent miscarriages (PRMs) are caused by non-chromosomal causes since the frequency of abnormal embryonic karyotypes is significantly lower in patients with SRM compared with PRM. In the present study, history of SRM was more frequently found in women who had given birth to a male previously $(p=0.004)$. A total of 34 patients suffered from secondary recurrent abortions. Almost two-third of these 23 had a first male baby. Only 11 had an earlier female child. Ooi PV et al $^{13}$ also did a similar study on patients of SRM. They found that SRM was more frequently preceded by the birth of a male child $(\mathrm{p}=0.002)$. Similar results were found by Nielsen HS et al14 and Christiansen OB et al. ${ }^{15}$

Nielsen HS et $\mathrm{al}^{16}$ did another study recently in 2011 , showing the male: female sex ratio of children born prior to SRM as 1.49 and of the children born subsequent to $\mathrm{SRM}$ as 0.76 . In the present study too, the male: female ratio of children born prior to SRM was more than that for the subsequent births i.e. 2.09 and 0.79 respectively, probably indicating that male fetuses are preferentially aborted. These abortions are supposed to be immunologically mediated related to presence of anti $\mathrm{H}$ $\mathrm{Y}$ immunity in the mother whose immune system has previously been sensitized by the $\mathrm{Y}$ mediated antigens of previous male fetus.

\section{CONCLUSIONS}

Anti H-Y immunity can be a possible explanation for recurrent abortions which otherwise remain unexplained by standard investigations. Further research is required in this regard so that immune based treatments can be devised for recurrent abortions.

Funding: No funding sources

Conflict of interest: None declared

Ethical approval: Not required

\section{REFERENCES}

1. Tulppala M, Palosuo T, Ramsay T, Miettinen A, Salonen R, Ylikorkala O. A prospective study of 63 couples with a history of recurrent spontaneous abortion: contributing factors and outcome of subsequent pregnancies. Hum Reprod. 1993;8:76470.

2. Katz VL, Kuller JA. Recurrent miscarriage. Am J Perinatol. 1994;11:386-97.

3. Jivraj S, Anstie B, Cheong YC, Fairlie FM, Laird $\mathrm{SM}, \mathrm{Li}$ TC. Obstetric and neonatal outcome in women with a history of recurrent miscarriage: a cohort study. Hum Reprod. 2001;16:102-6.

4. Quenby SM, Farquharson RG. Predicting recurring miscarriage: what is important? Obstet Gynecol. 1993;82:132-8.

5. Unander AM, Norberg R, Hahn L and A rfors L. Anticardiolipin antibodies and complement in ninety-nine women with habitual abortion. Am J Obstet Gynecol. 1987;156:114-9.

6. Xu L, Chang V, Murphy A, Rock JA, Damewood M, Schlaff W, et al. Antinuclear antibodies in sera of patients with recurrent pregnancy wastage. Am J Obstet Gynecol. 1990;163:1493-7.

7. Hill JA, Polgar K, Harlow BL, Anderson DJ. Evidence of embryoand trophoblast-toxic cellular immune response(s) in women with recurrent spontaneous abortion. Am J Obstet Gynecol.1992;166:1044-52.

8. Aoki K, Kajiura S, Matsumoto Y, Ogasawara M, Okada S, Yagami Y and Gleicher N. Preconceptional natural-killer activity as a predictor of miscarriage. Lancet. 1995;345:1340-2.

9. Kruse C, Rosgaard A, Steffensen R, Varming K, Jensenius JC, Christiansen OB. Low serum level of mannan-binding lectin is a determinant for pregnancy outcome in women with recurrent spontaneous abortion. Am J Obstet Gynecol. 2002;182:1313-20.

10. Pfeiffer KA, Fimmers R, Engels G, Ven H VD, Ven $\mathrm{K}$ VD. The HLA-G genotype is potentially associated with idiopathic recurrent spontaneous abortion. Mol Hum Reprod. 2001;7:373-8. 
11. Kruse C, Steffensen R, Varming K, Christianen OB. A study of HLA-DR and -DQ alleles in 588 patients and 562 controls confirms that HLA-DRB $1 * 03$ is associated with recurrent miscarriage. Hum Reprod.2004;19:1215-21.

12. Christiansen OB, Pedersen B, Nielsen HS, Andersen AM. Impact of the sex of first child on the prognosis in secondary recurrent miscarriage. Hum. Reprod. 2004;19(12):2946-51.

13. Ooi PV, Russell N, O'Donoghue K. Secondary recurrent miscarriage is associated with previous male birth. J Reprod Immunol. 2011;88(1):38-41.
14. Nielsen HS, Andersen AM, Kolte AM, Christiansen OB. A firstborn boy is suggestive of a strong prognostic factor in secondary recurrent miscarriage: a confirmatory study. FertilSteril. 2008;89:907-11.

15. Christiansen OB, Nielsen HS, Steffensen R. Association of HY-restricting HLA class II alleles with pregnancy outcome in patients with recurrent miscarriage subsequent to a firstborn boy. Hum Mol Genet. 2009;18(9):1684-91.

16. Nielsen HS. Secondary recurrent miscarriage and HY immunity. Hum Reprod Update. 2011;17(4):55874.

Cite this article as: Raina D, Prashar N, Sharma G. Secondary recurrent miscarriage and sex of previous child. Int J Reprod Contracept Obstet Gynecol 2016;5:1621-4. 